https://doi.org/10.30843/nzpp.2018.71.190

\title{
Susceptibility of kale cultivars to the wheat bug, Nysius huttoni (Hemiptera: Lygaeidae) in New Zealand
}

\author{
Sundar Tiwari ${ }^{1,3,}$, David J. Saville ${ }^{1,2}$ and Stephen D. Wratten ${ }^{1}$ \\ ${ }^{1}$ Bio-Protection Research Centre, PO Box 85084, Lincoln University, Lincoln 7647, New Zealand \\ ${ }^{2}$ Saville Statistical Consulting Limited, PO Box 69192, Lincoln 7640, New Zealand \\ ${ }^{3}$ Agriculture and Forestry University, Department of Entomology, Bharatpur 44200, Nepal \\ ${ }^{*}$ Corresponding author: Sundar.Tiwari@lincolnuni.ac.nz
}

Seedlings of kale cultivars are highly susceptible to direct feeding by the wheat bug Nysius huttoni (Hemiptera: Lygaeidae), an endemic New Zealand insect pest. Damage from this pest leads to reduced plant establishment so is currently managed by prophylactic use of pesticides. Encouraging farmers to use less susceptible kale cultivars can reduce pesticide costs and improve the environment. A series of choice and no-choice tests was conducted in a controlled-temperature room to evaluate the relative susceptibility of seedlings of the six most widely grown kale cultivars in New Zealand (Gruner, Kestrel, Regal, Colear, Corka, and Sovereign). Bugs settled most readily on Kestrel in both sets of tests, although mean settlement times did not differ significantly among cultivars. However, feeding damage on Kestrel occurred significantly earlier than on Corka or Gruner. These results indicate that Kestrel is the cultivar most susceptible to wheat bugs and that pesticide use could be reduced if less susceptible cultivars were more widely grown in New Zealand. These results also provide important information for developing integrated-management protocols for brassica pests.

https://doi.org/10.30843/nzpp.2018.71.203

\section{What's buzzing? A snapshot analysis of pest notifications}

\author{
Prasad Doddala ${ }^{1, \star}$, James Haw ${ }^{2}$, Santha France ${ }^{1}$, Diane Anderson ${ }^{2}$, Milen Marinov ${ }^{1}$ and Alan Flynn ${ }^{1}$ \\ ${ }^{1}$ Plant Health and Environment Laboratory (PHEL), Biosecurity New Zealand, PO Box 2095, Auckland 1140, New Zealand \\ ${ }^{2}$ PHEL, Biosecurity New Zealand, PO Box 14018, Christchurch 8544, New Zealand \\ ${ }^{*}$ Corresponding author: Prasad.Doddala@mpi.govt.nz
}

The Ministry for Primary Industries' PHELs receive many notifications each year of pests suspected of being new to New Zealand. Most notifications are received through the Ministry's free Pest and Disease Hotline and are an important source of surveillance data. During the period January 2015-February 2018, PHELs received $\sim 9400$ notifications, with each March the busiest $(1,160)$ period. Fifty-one percent of notifications came from Auckland, Waikato or the Bay of Plenty. The brown soldier bug, Cermatulus nasalis, was the most frequently reported (483) invertebrate. Publicity campaigns targeting specific pests (e.g. brown marmorated stink bug), past incursion-response publicity (e.g. fruit flies, termites) and 'strange-looking' invertebrate notifications are all reflected in the organisms reported. Excluding targeted campaigns and incursion responses, guava moth, Coscinoptycha improbana $(181 ; \sim 2 \%)$, was the most frequently reported, followed by the three-lined hover fly, Helophilus seelandicus ( $97 ; \sim 1 \%)$. Spiders, as a group, were reported in considerable numbers (14.4\%). Ant samples were frequently submitted (9.1\%). These data indicate the number of notifications geographically is proportional to human-population levels. These results will assist PHEL in planning and engaging in future surveillance initiatives. 